\title{
Ebola virus outcomes
}

\section{Gude Himabindhu*}

Department of Biotechnology, Osmania University, Hyderabad, Telangana, India

Correspondence to: Gude Himabindhu, Department of Biotechnology, Osmania University, Hyderabad, Telangana, India

, Tel: 8143389651; E-mail: smily.bindu20@gmail.com

\section{Ebola Virus}

Ebola virus is infection is rare but a deadly disease that occurred in the African countries. Viruses like Ebola, Sudan, Taï Forest, and Bundibugyo viruses cause disease in people.

In 1976, Ebola virus was first discovered. There is no evidence of ebola virus infection but scientists believe that the ebolavirus is animal borne, with bats, apes, monkeys, chimpanzees, etc. (non-human primates). Infected animals will carry the virus to transmit it to the other animals.

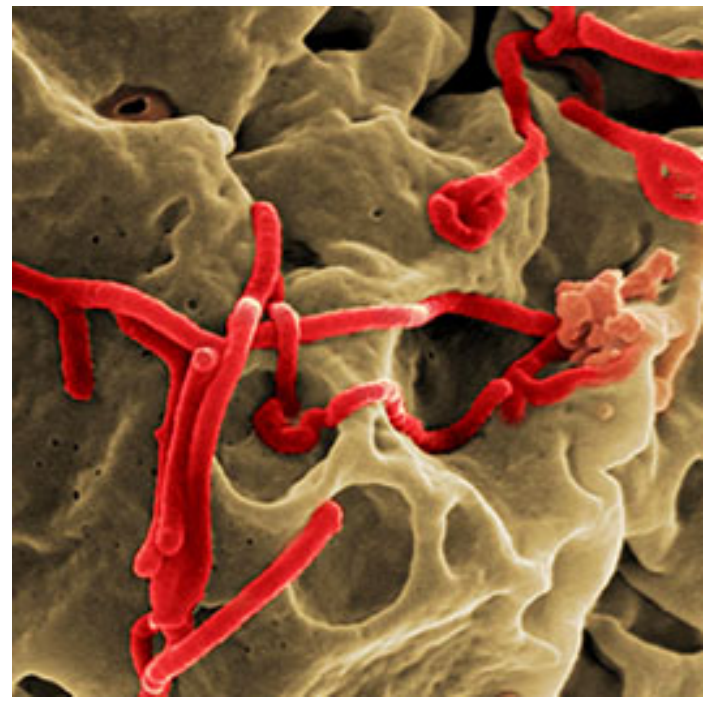

Figure 1: Ebola virus infection.

The virus also spread to humans through direct contact with blood, blood fluids. Virus can also transmit through sexual contact.

Transmission of disease can also be from the use from the contaminated syringes and needles during the 1st outbreak in Zaire (Democratic Republic of Congo).

Symptoms of Ebola virus includes fever, aches and pains, weakness, fatigue, gastro problems, diarrhoea, vomiting, bleeding, redness in eyes, rashes on skin, hiccups.

Prevention of ebolavirus infection includes hand hygiene like washing hands with soaps, water, alcohol based sanitizers. Hand hygiene lowers the spread of disease.
Self-isolation from public had a less risk in the spread of disease.

Diagnosis of Ebolavirus is a bit difficult. PCR (Polymerase Chain Reaction) is one of the most common diagnostic method but not effective.

On 1st june 2020 Democratic Republic of the Congo of Ministry of Health declared Ebola virus disease (EVD) as 11th outbreak.

The first case of EVD occurred in 2013 in guinea. An 18 months old boy died in December and the disease transmission has started. In 2014 causing of the disease is identified as Ebola virus. Epidemic of EVD is on-going in 2014 in Sierra Leone, Guinea, and Liberia. Nigeria and Senegal had small outbreaks from neighbouring countries. Several death cases were reported from Mali. By March 2016 11,325 cases were confirmed and suspected death occurred.

The outbreak of Ebola virus in West Africa has ended in 2014-2016.

Ebola virus disease has no cure, plasma transfusions from recovering patients and an experimental antibody preparation have been used to treat patients.

Ebola virus vaccine trials are in progress. The two front-running vaccine candidates are a GSK (in the Phase 2 trial) chimpanzee adenovirus vector vaccine (including several versions of it) and a Merck/NewLink Genetics recombinant vaccine. The trials were supported by NIAID/NIH.

The Ebola vaccine licensed by NewLink Genetics in Ames, lowa, was originally developed by the Public Health Agency of Canada.

Johnson \& Johnson has a prime-boost Ebola vaccine is in development stage. This two-phase strategy starts with direct exposure to DNA (the "prime") followed by offering the same or similar antigen in a virus that does not replicate well in human tissue ("the boost"). This approach has been shown in a variety of settings to yield a robust immune response to the antigen of interest.

In many cases, the trials participants will be are those at high risk of contracting disease, such as healthcare workers and family members of people who have EVD.

How to cite this article: Himabindhu G. "Ebola virus outcomes". J Infect Dis Med 5 (2020) doi: 10.37421/jidm.2020.5.144 